\title{
Actors and interpretations in an environmental controversy: the Swedish debate on sewage sludge use in agriculture
}

\author{
Magnus Bengtsson*, Anne-Marie Tillman \\ Environmental Systems Analysis, Chalmers University of Technology, SE-412 96 Göteborg, Sweden
}

Received 15 April 2003; accepted 25 February 2004

\begin{abstract}
This study examines the Swedish debate on the sustainability of using sewage sludge as fertiliser in agriculture. Although the use of sludge as fertiliser presents potential resource and environmental advantages, it can have negative effects on people and soil productivity. Both proponents and opponents of agricultural application of sludge use environmental arguments to support their positions. By 1990, the Swedish parliament stressed the importance of recycling nutrients from wastewater; however, despite low levels of contamination, compared to other countries, little sludge is used in agriculture today.

During the last few decades, a large amount of research has addressed the risks and benefits of using sludge as fertiliser, but the central actors have not been able to reach lasting agreements. This study, which is based on document analysis, direct observations, and interviews, analyses the beliefs, preferences, and arguments of major actors in the national debate on sludge. The study investigates how actors define problems and interpret the risks and benefits of sludge use. Specifically, the study concentrates on the role of science in the sludge controversy. Two distinct ways of thinking-a precautionary frame and a proof-first frame-are identified. These frames are shown almost immune to factual claims and arguments from opponents. It is concluded that actors in the controversy need to address explicitly value judgements and beliefs that go beyond scientific information. In addition, the study concludes that there is a need for policy makers to further develop process leadership skills. (C) 2004 Elsevier B.V. All rights reserved.
\end{abstract}

Keywords: Environmental controversy; Sewage sludge; Agriculture; Risks; Scientific information; Frames

\footnotetext{
* Corresponding author. Present address: Department of Urban and Environmental Engineering, The University of Tokyo, 7-3-1 Hongo, Bunkyo-ku, Tokyo 113-8656, Japan. Tel.: +81-3-5841-6249; fax: +81-3-5841-8533.

E-mail address: magnus@env.t.u-tokyo.ac.jp (M. Bengtsson).
} 


\section{Introduction}

Each year, municipal wastewater treatment plants in Sweden generate around 230,000 metric tonnes of sewage sludge (measured as dry matter). The sludge is a waste product that municipalities need to dispose and a potential resource due to its content of plant nutrients and other soil improving substances. Sludge use in agriculture solves the disposal problem and makes use of the valuable constituents. For a long time, however, this has been a contested practice. This study examines the debate on sludge use and the attempts to work out sustainable solutions.

The agricultural use of sludge has reduced farmers' need for mineral fertilisers and has improved soil structure. Farmers have often received the sludge at no cost making the use of sludge economically attractive. Hence, ever since the construction of wastewater treatment systems in Sweden, which took place mainly in the 1950s and 1960s, a great amount of sludge has been spread on farmland, albeit with large regional variation. Because sewage sludge contains harmful and potentially hazardous substances, some actors oppose its use in agriculture, and with varying degrees of intensity, the advantages and disadvantages of sludge use in agriculture have been debated since the late 1960s. As a consequence of the lengthy debate, some actors are now tired of the issue and what appears to be a deadlock. Despite the difficulties in reaching agreements, the use of sludge is still of topical interest for several reasons:

- the political emphasis on the recycling of nutrients as part of a sustainable development;

- the economic benefits of sludge use in agriculture for both municipalities and farmers;

- the drawbacks of alternative sludge handling options in addition to their higher costs.

The sludge debate reflects a goal conflict in Swedish environmental policy. To guide society in a sustainable direction, the parliament has decided on 15 environmental quality objectives. The sludge issue is related to three of these objectives, according to which waste should be recycled so that the need to extract resources is minimised; the environmental concentrations of toxic substances should be close to naturally occurring levels; and the long-term production capacity of arable land should be preserved. The use of sludge in agriculture is motivated by the first of these objectives, but it may go against the latter two. We consider it essential to investigate how society handles this kind of environmental goal conflicts.

Sludge is spread in agriculture in most European countries, but variations are large (EEA, 2002). Opposition is growing in some countries, which has given rise to debates similar to the one in Sweden (Bowler, 1999; EC, 2001). We believe that actors involved in sludge controversies in other countries may learn from the Swedish experience.

This article analyses the interpretations, arguments, and policy positions of actors engaged in the Swedish sludge controversy. Many studies of controversies have concentrated on internal scientific debates (Engelhardt and Caplan, 1987; Brante et al., 1993). We do not approach the sludge controversy as a scientific debate, but as what Brante (1990) calls a science-based controversy - a dispute about the common good in which scientific authority plays an important role. In such a controversy, it is of central interest to investigate how actors use scientific information and to what degree they seem to think that scientific information can resolve the issue. The results of such an analysis can be used to suggest ways the controversy may be better understood and more constructively addressed. 


\subsection{Previous research}

A great deal of research has been conducted on the technical and natural science aspects of sludge use in agriculture. That literature is not reviewed here, although some studies will be mentioned in the analysis. However, the social side of sludge management and the debate per se have not been researched in detail. In a review article on sludge management, Krogmann et al. (1997) noted that

despite a diverse and growing literature on public perception and acceptance of risks associated with waste management decisions, surprisingly few studies examined perception and acceptance of risk relative to land application of biosolids (sludge that fulfils specific quality standards).

Krogmann et al. found that studies on this subject were mostly isolated case studies with few general conclusions. However, a recurring theme in those studies was the role of trust in obtaining public acceptance for sludge application. Similar conclusions have been made in Swedish studies. Hultman et al. (2000) briefly reviewed the debate and Berglund (2001) investigated the position of the food industry. Other Swedish studies have focused on the municipal level (Söderberg, 1999) and on a major environmental non-governmental organisation (Lönngren, 2004).

\subsection{Methods and materials}

The present study examines the national sludge debate. Consequently, most empirical material is related to national actors such as federations, associations, and public authorities. Information has been collected using document analysis, direct observations at meetings and seminars, and personal interviews. This diverse material is analysed to find answers to the main questions of the study: what is the role of scientific information and what are the structural properties of the deadlock?

\subsection{Recent events}

In October 1999, the Federation of Swedish Farmers (LRF) recommended its members to stop using sludge, thereby breaking the sludge agreement that had been in place since 1994. The initiating factor was the increasing concentrations of brominated flame-retardants (BFR) found in sludge, something which had been highlighted by the Swedish media, including the national TV network. The LRF's decision was also influenced by earlier reports on accumulation of silver in soils where sludge was spread and on hygienic risks related to wastewater from hospitals. The other parties of the sludge agreement were the Water and Wastewater Association $\left(\mathrm{VAV}^{1}\right)$ and the Environmental Protection Agency (NV). As a result of the LRF's recommendation, the use of sludge in agriculture dropped significantly from about $25-30 \%$ in the late 1990s to just over 10\% in 2001 (Johansson, 2002).

\footnotetext{
${ }^{1}$ VAV is the old acronym for the Swedish Water and Wastewater Association. From 1 January 2002 it has been called Svenskt Vatten. For simplicity, the old acronym is used in this paper.
} 
The farmers' increased reluctance to use sludge caused problems for the municipalities. The government was just about to introduce a tax on landfilling of organic waste, with the explicit purpose of creating incentives for recycling. Furthermore, it had been announced that the tax would be replaced by a ban in 2005. Because the LRF's recommendation had strongly limited the use of sludge in agriculture, the municipalities saw no realistic prospects for complying with the national ambitions to increase recycling. Hence, the municipalities demanded, through the VAV, clearer guidelines from the government and the public authorities. As a consequence, in the spring of 2001 the NV was commissioned to investigate the policies on sludge and recycling of phosphorus. The investigation would compile the best available knowledge and, in co-operation with other public authorities and relevant organisations, work out an action plan with time-set target levels for recycling.

\section{The sludge/nutrients network}

The sludge controversy is a concern for several actors and involves more than just the wastewater sector and the farmers. Fig. 1 shows the actors directly involved in the recycling of phosphorus when sludge is used in agriculture. Sorting and separating technologies lead to similar flows.

The arrows in Fig. 1 illustrate flows of phosphorus. Bold arrows indicate the recycling route in relation to sludge. The grey boxes show what activities or actor groups are directly involved in handling the flow. In addition to the actors who are physically involved, other actors such as public authorities and non-governmental organisations (NGOs) affect how

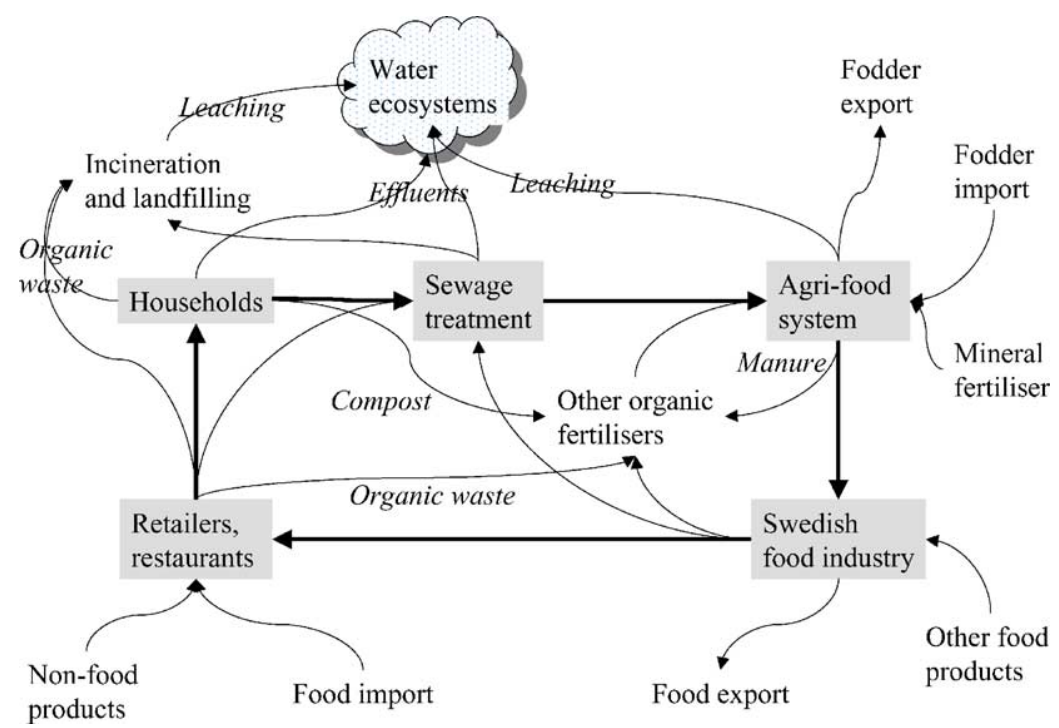

Fig. 1. Activities and actors involved in the circular flow of phosphorus promoted by the Swedish national policy. 
sludge is handled. The main actors in the controversy and their positions on sludge use are presented below.

\subsection{The political system and public authorities}

The Environmental Protection Agency (NV) is the national authority responsible for environmental and resource conservation issues, which includes sludge management and phosphorus recycling. To implement the national policy objective of increased recycling, the NV strives to work out control measures. One such measure is the set of limit values that regulate how sludge may be used on farmland. These limit values were the basis for the voluntary sludge agreement that was broken in 1999. Although the LRF has left the agreement, the regulations are still valid. As long as these regulations are followed, the spreading of sludge is legal.

Apart from the NV, other national public authorities have concerns about the use of sludge in agriculture: the Chemicals Inspectorate, the National Food Administration, the National Veterinary Institute, the Swedish Board of Agriculture, and the National Board of Health and Welfare. To varying degrees, these public authorities are active in the debate, but they are typically more restrictive to the use of sludge as fertiliser than the NV.

\subsection{The wastewater sector}

All treatment facilities for municipal wastewater in Sweden are publicly owned. In most municipalities, a separate department operates the plants although in some cases publicly owned companies carry out this task. Private companies have only recently entered the plant operation business. All municipalities are members of the Swedish Water and Wastewater Association (VAV). Compared to other countries, the Swedish water and wastewater sector is relatively decentralised; many decisions are made at the municipal level. Because most municipalities are too small to employ specialists in sludge treatment, there is a great need for co-operation and dissemination of knowledge. The VAV is an important body for such collaboration. There is also a large market for technical consultants to assist the municipalities. At the same time, however, the sector is highly regulated: national legislation and directives from the provincial governments have strongly influenced the historical development of the sector.

The municipalities seek affordable, reliable, and environmentally sound solutions for sludge disposal, to solve the problem at least in the near future. Some municipalities view agricultural use of sludge as a beneficial and feasible option, whole others believe that alternative solutions must be worked out. At the national level, however, the VAV prefers the use of sludge in agriculture.

\subsection{The farmers}

The farmers are a diverse group with divergent opinions on the use of sludge. However, this paper deals mainly with the national organisation that represents the farmers: the LRF. About $80 \%$ of the farmers are members of this federation. Apart from being the farmers' co-operation and lobbying organisation, the LRF also owns the Swedish Agriculture Co-operatives, which include a large part of the Swedish food industry. The farmers 
and the food industry are thus closely linked by a seller-buyer relationship and through a co-operative ownership. As mentioned above, the LRF recommends its members not to use sludge, but it has previously supported agricultural use. Because not all farmers are members of the federation and because it is only a recommendation, sludge is still being spread in some regions.

\subsection{The food industry}

Many food companies have accepted the use of sludge in the past, but since the LRF no longer supports the sludge agreement, the situation has changed. Today, almost no companies are willing to buy cereals or other food products from farms that use sludge. By accepting sludge use, the food industry only gains a negligible economic advantage. The industry, however, takes an economic risk because new negative reports may affect consumer confidence in food from sludge fertilised agriculture.

\subsection{The consumers}

Surveys have shown that consumers do not have a clear opinion on whether sludge use in agriculture is acceptable or not; in general, the informants say that more information is needed (Berglund, 2001). In the national debate on sludge, consumers are represented by two organisations: the Swedish Consumer Coalition (SKiS) and the Swedish Consumers' Association (SKR). Unlike some other countries, the consumer movement in Sweden is not powerful, and it is seldom visible in public debates. Thus, the organisations are not well known by the public. Traditionally, the public authorities have been regarded as the main protectors of public health. The SKiS is the more radical of the two organisations and the one that is the most active in the sludge debate. They strongly oppose the use of sludge, mainly for health reasons.

\subsection{The environmental movement}

The Swedish Society for Nature Conservation (SNF), which is the country's largest environmental NGO, is also engaged in the debate. The SNF generally does not support agricultural use of sludge. However, there has been an intense debate within the SNF on the sludge issue. Until 1996, the SNF supported the agreement between the NV, the VAV, and the LRF (Lönngren, 2004). The disagreement among environmentalists is significant because it shows that the sludge controversy is not of the traditional "environmental protection versus economic development" type, but it is also based on conflicting interpretations of what is preferable from an environmental point of view. Other environmental organisations such as Greenpeace and Friends of the Earth are not actively involved in the national debate at present.

\subsection{Other actors}

The Swedish food eco-label KRAV does not allow contracted farmers to apply municipal sewage sludge to their fields. In 2001, about $13 \%$ of the farmland were cultivated according to 
organic principles; this is increasing. The national policy wants $25 \%$ of all cereals produced to be organic by the end of 2005 (SEPA, 2001).

Over the years, the media have focused on contaminants in sludge and local protesters. Nutrient recycling does not have the same news value and has received much less attention.

\section{The contested issues}

The sludge debate involves several contested issues related to both the potential risks of spreading sludge on farmland and to the benefits of recycling nutrients.

\subsection{Metals}

Today, the concentrations in sludge of seven metals - $\mathrm{Cd}, \mathrm{Pb}, \mathrm{Cu}, \mathrm{Cr}, \mathrm{Hg}, \mathrm{Ni}$, and $\mathrm{Zn}-$ are monitored regularly. For these elements, there are limit values to regulate sludge use in agriculture. Many other metals, however, are also present in sludge and some of these metals have attracted attention recently because of their rapidly increasing concentrations in soil. These rapid increases are due to very low naturally occurring concentrations. Some of these unregulated metals such as silver are known to have negative effects while for other metals little is known about their behaviour in soil and their biological effects. All actors agree that systematic increases of concentrations of metals are unacceptable. However, they do not agree on safety margins or on the urgency of reducing metal flows to soil.

\subsection{Organic pollutants}

Organic pollutants differ from metals in two essential respects: their number and degradability. While the metals are a small number of well-specified elements, the organic pollutants that may be present in sludge can be counted in tens of thousands. Furthermore, many new chemicals are produced every year. Many of these compounds are not harmful or degrade rapidly into harmless and naturally occurring substances. Some, however, are persistent and harmful even in low concentrations. Only for a minority of these substances are the biological effects well investigated. The actors do not agree on how the risks caused by this group of pollutants should be assessed.

\subsection{Pathogens}

Bacteria, viruses, fungi, and parasites may be present in sludge. Through sludge treatment, these can be reduced; however, their complete elimination requires advanced treatment and only under special conditions can this be fully guaranteed. Like in the case of metals and organic pollutants there is no agreement among the actors whether pathogens may cause problems if sludge is used in agriculture. Stricter EU regulations are expected in the near future.

\subsection{Nutrients}

Phosphorus is a vital element for biological production. Society needs to be careful with available phosphorus, since the easily accessible and relatively unpolluted deposits of 
phosphorus-rich minerals are limited, and because of the global demand for phosphorus as fertiliser will remain high. Thus, the Swedish parliament has stressed the need for recycling phosphorus from organic waste. Phosphorus is the nutrient that is given most attention in the sludge debate, but some actors such as farmers and researchers also talk about the need for recycling nitrogen, potassium, sulphur, and various micronutrients. Although all actors in the controversy agree that, in the long run, the recycling of phosphorus and other nutrients ought to be encouraged, they have different opinions on how urgent recycling is and to what degree the benefits can compensate for the risks.

\section{Present options for sludge handling}

The opposition against sludge use in agriculture has caused municipalities to look for other options. Table 1 describes the main alternatives considered.

Only options 5 through 10 in Table 1 fulfil parliament's goal to recycle phosphorus. All three separating technologies (6-8) need further full-scale testing before they can be considered realistic options. The sorting alternatives ( 9 and 10) cannot be implemented in the short run because they require major re-constructions of existing buildings and infrastructure. Presently, the municipalities need advice on how to take care of the sludge in the short run, and they need directives to guide their long-term planning and investments.

Table 1

Sludge treatment options considered

1. Landfilling

2. Soil production

3. Forest fertilisation

4. Incineration

5. Spreading on farmland

6. Sludge separation

7. Separation of ashes after incineration

8. Super critical water oxidation

9. Urine sorting

10. Separate black-water system
Has been widely used as a complement to spreading for polluted sludge and in areas where there has been no demand for sludge in agriculture. Not allowed from 2005 The use of sludge for other purposes than agriculture such as parks, flower plantations, embankments for noise reduction, and golf courses has increased in recent years. For increased growth in both coniferous forests and plantations of energy crops such as Salix The remaining ashes are not classified as organic waste and are thus not affected by the ban on landfilling

Recycles nutrients to soil, an inexpensive and technically well-tested option

Makes the phosphorus available for recycling. The technology is still under development Makes the phosphorus available for recycling. The technology is still under development Makes the phosphorus available for recycling. The technology is still under development Makes a large portion of the nutrients available for recycling. Requires the installation of special WCs and separate piping for collection Water from WCs handled separately from other streams of liquid waste. Requires special installations and separate piping 


\section{Analysis}

Several factors contribute to the intractability of the sludge controversy. This analysis identifies and discusses some of those factors. To this end, two main themes are examined. The role given to science and scientific information, and the structural properties of the controversy. Emphasis is placed on the present deadlocked situation. The study also examines what the situation would be like if sludge were widely accepted for use in agriculture.

\subsection{The role of science and facts}

One of the issues that have been discussed the most and the longest in the sludge controversy is the health effects of heavy metals, most notably cadmium. Although these elements have been on the agenda for more than 30 years, the actors interpret available scientific information in different ways. The VAV writes as follows in an official comment on the report "Products without hazards" (Varor utan faror) written by the NV:

Scientific investigations come to the unambiguous conclusion that bringing nutrients back to farmland through the spreading of sludge does not entail any problems in the short or medium run, while the accumulation of heavy metals may become a problem in the long run ...

The consumer organisation SKiS presents a completely different view in a recent report on metals in sludge:

The amount of cadmium in the soil is today so high that further increases must be prevented, even if this requires large sacrifices. Increasing concentrations in soil lead to higher concentrations in food products and in human's kidneys. Today, the concentrations are on a level where kidney specialists say that there are no margins left; risk groups are already believed to have damaged kidneys.

The quotations above show that the VAV and the SKiS draw different conclusions as to the urgency of reducing flows of heavy metals to agricultural soil. The quotations also show that they both claim to have scientific support for their positions. To some degree, this disagreement reflects a lack of consensus among scientists; for example, in a review article, McLaughlin et al. (1999) noted that there "still [is] a considerable debate in the scientific literature as to the chronic effects of lifetime exposure to low levels of $\mathrm{Cd}$ in foods ...". Ekvall (1995), who investigated the behaviour and toxicity of metals in sewage sludge when applied to farmland, found that generally it is difficult to predict plant uptake and soil toxicity from measurements of metals in sludge. Similarly, Palmquist (2001) noted the difficulties of assessing the chemical risks associated with wastewater systems.

Although the VAV and the SKiS judge the severity of heavy metals differently, they strongly believe that decisions made about the handling of sludge can be based on science and facts. For example, in a letter to the Minister of the Environment, the VAV writes as follows:

The sludge issue has been subject to many beliefs, most of which lack factual grounding and are based on feelings. We think it is absolutely necessary that a long-term sustainable strategy be based on science. 
This reliance on facts is shared by the SKiS. This is evident in what they write on their web site:

[W] e have ... been able to uncover truths that would otherwise have been hidden from us, and an impressive amount of facts, that will for sure be scrutinised and refuted by those who have things to lose from the exposure of unpleasant truths.

These two quotations also illustrate the lack of mutual trust between the actors.

Limit values established by the NV is the major policy instrument to regulate the use of sludge in agriculture; however, as illustrated by the following two quotations, both the VAV and the SKiS criticise these values for not being based on science. Thus, in the SKiS's official comment on the report "Products without hazards," it reads as follows:

The limit values mentioned in the draft are based on pragmatic considerations and on the existing levels in sludge, and have hardly anything to do with environmental protection, health or sustainable agriculture. Those values have been decided in order to enable the spreading of sludge.

Similarly, the VAV writes in a letter to the Ministry of the Environment that the limit values are "a negotiation product, against which many objections may me raised on scientific grounds".

Although both these actors hold that the limit values are not sufficiently based on science, they come to opposite conclusions as to how the values ought to be adjusted. This view on limit values further illustrates how these two actors overly emphasise science. The NV acknowledges that the limit values are not based on rigorous risk assessments, but are based on what is technically feasible to achieve. The idea is that limit values help distinguish between more and less polluted sludge, and that stricter and stricter values will lead to decreasing amounts of contaminants.

\subsection{What qualifies as a problem?}

The actors in the debate have different views on what kind of information indicates a problem. For example, the SKiS believes that increasing concentrations of metals or organic pollutants in sludge are indications that there may be problems. As noted above, increasing concentrations of brominated flame-retardant caused the LRF to change its recommendation on sludge. These actors both represent a precautionary frame. This is illustrated by the following quotation, taken from a recent report published by the SKiS.

No element may be left out beforehand; all increases in concentrations should be viewed as potentially dangerous, since we cannot remove the metals afterwards or foresee their fate in soil.

In contrast, the VAV represents a proof-first frame, which is reflected in a letter to the Minister of the Environment.

To demand, for ethical reasons, that the concentrations of unwanted substances should be on background levels may render sludge fertilisation impossible, even though there are no real risks to the environment or to human health. 


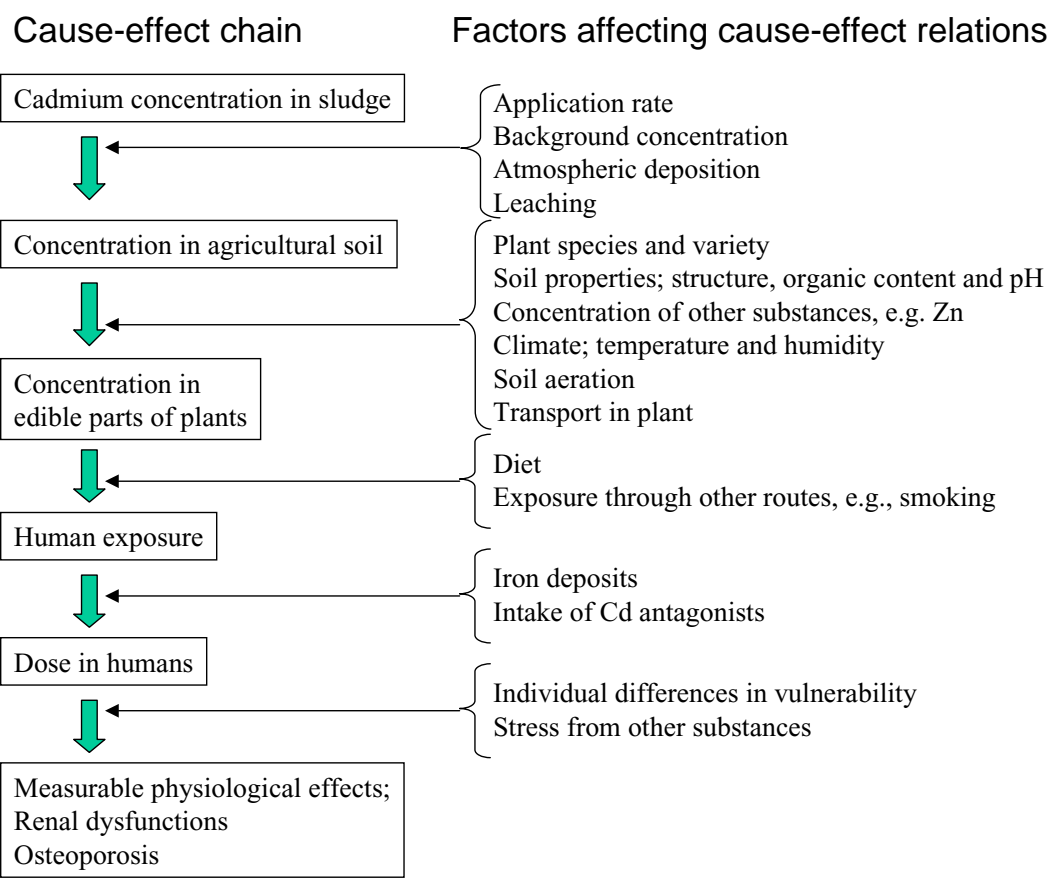

Fig. 2. A model of causes and effects linking cadmium in sewage sludge to adverse health effects. The figure also shows selected factors that affect whether or to what extent one level in the cause-effect chain actually affects following levels.

The case of cadmium can be used to illustrate the complexity of assessing the relation between contamination of sludge and adverse health effects (Fig. 2). Measured results on any of the levels in the cause-effect chain can be interpreted by one actor as an indication of adverse effects, but that interpretation can very well be disputed by other actors who do not have the same view on how cause-effect relations are influenced by various factors. As noted above, the uncertainties around some of these factors are substantial. When actors do not agree on this underlying level, they have problems convincing each other: what one actor perceives as salient information and sound arguments are often not at all persuasive to other actors.

As has been illustrated by heavy metals, there are large variations in actors' interpretations of the health risks of applying sludge to farmland. Similar observations could have been made for organic pollutants and pathogens. However, in the debate on sludge, various ideas are also present about the importance of recycling phosphorus. The view of the SKiS can be contrasted with that of the NV. On the SKiS's web site, it is argued that "phosphorus belongs to the 10 most common elements in the Earth's crust, oxygen not included, and there are incredible amounts in the bedrock". The NV expresses a rather different view in a follow-up report on the environmental objectives: "Phosphorus is an essential element that is in very short supply". 


\subsection{Frames and interpretations}

The precautionary and proof-first frames mentioned above are coherent systems of beliefs and knowledge (Schön and Rein, 1994). These frames or world-views can best be described in the form of short narratives, which illustrate how individuals using these frames typically interpret the problems and opportunities related to sludge and nutrients.

The precautionary frame. Society is full of substances that we cannot control. Some of these will be present in sludge and accumulate in soil if sludge is spread. We do not have, and will never have, sufficient knowledge about the behaviour and effects of all these substances. Because the pollution of farmland is irreversible, the soils must be protected. For some substances, there are small or no safety margins left, which means that the use of sludge must be stopped immediately. Furthermore, the shortage of phosphorus is exaggerated. In the short run, mineral fertiliser, which is far less polluted than sludge, is a good option. In the end, sorting systems should be installed so nutrients from food may safely be recycled in a natural form. If we make the necessary decisions now, the old systems can be replaced within a few decades.

The proof-first frame. Society is full of potentially harmful substances. However, we can identify the most hazardous ones and regulate their use. The worst substances should be banned. Through continuous improvements, the quality of the sludge can be assured. By building barriers, we can protect the sewage systems from inflows of unwanted substances, thereby protecting the quality of the sludge. Such barriers can be either physical or based on increased knowledge and awareness among the users. Safety margins are large, but improvements are needed to safeguard against future problems. Recycling of phosphorus and other nutrients is an important societal goal, and spreading of sludge is the most cost efficient and best option for achieving that goal. Moreover, replacing the existing wastewater systems with sorting ones is extremely costly and would take more than 50 years.

The precautionary narrative fits well with the positions of environmental and consumer NGOs. The proof-first narrative is typical of what a representative of the VAV would say and it resembles the traditional position of the NV. The LRF is more ambiguous and hard to place in any of these two distinct ways of thinking; they combine elements of precaution with an emphasis on recycling.

\subsection{Interpretations of results from flow models}

In their investigation of sludge and phosphorus policies, the NV has commissioned studies to compare sludge treatment options in a life-cycle perspective. These studies use flow models for analysing the potential recycling of phosphorus for a range of options. The associated costs, energy consumption, and emissions to air and water are also investigated. The basis for comparison in these studies is the flow of recycled phosphorus. This means that costs, energy, and emissions are expressed per kilogram of phosphorus being recycled. This way of evaluating the systems makes sense to the NV and wastewater sector. However, the farmers think that these studies compare dissimilar things because differences in contamination of nutrient flows are not taken into account properly. While some options generate more or less pure phosphorus, others produce fertilisers that are, to varying 
degrees, polluted. From the farmers' point of view, it would be more relevant to compare options that can produce unpolluted nutrients. Furthermore, the studied systems do not only differ with respect to contamination, but also to the capacity to recycle other nutrients than phosphorus: nitrogen, potassium, and sulphur. A comparison focused solely on the recycling capacity for phosphorus does not consider these differences, something pointed out by both the farmers and the wastewater sector. When comparing technical systems, a basis of comparison that describes the main function of the systems is needed; however, as noted above, the systems investigated differ in many ways. Depending on perspectives, actors emphasise the importance of these other aspects of performance differently, and may thus have divergent views on the relevance of the modelling results for sludge policy.

\subsection{Sludge and nutrients: two separate policy issues?}

As indicated, the debate on sludge has several features that impede the process towards viable agreements. One such feature is the combination of two different policy issues:

(a) How should sewage sludge be taken care of in sustainable ways?

(b) How should agriculture be supplied with nutrients in sustainable ways?

Although these two issues are often discussed concurrently, they do not need to be connected. By combining the two, there is a risk that the discussion on nutrients is restricted to the present sewage systems that generate sludge. The issue of nutrient recycling, when handled on its own, is more open to alternative solutions such as sorting sewage systems and policies aimed at increasing the recycling of nutrients from other organic waste fractions. Hence, by combining the two issues, there is a risk that the policy process is biased towards only a subset of possible options.

Furthermore, because of actors' relations to the physical flows of sludge and nutrients, some actors feel more affected by and responsible for one of these two issues than the other. An example is the food industry, which is more concerned about the nutrients issue than about the sludge disposal. Therefore, the actors involved do not form a policy community focused on one policy problem, but rather form a mixed sludge/nutrients network in which actors have concerns about different issues. These conditions help explain why it is difficult to engage actors in joint problem solving.

\subsection{Agreements on principles: a way to resolve controversies?}

The actors in the sludge controversy emphasise scientific information, but they come to different conclusions on the implications of scientific results. Actors in controversies often ask for more and better information in expectation that this to help resolve the issue. However, new information can actually reinforce existing divergent beliefs of actors rather than bringing them closer. One way of resolving such situations is to look for agreement on the level of principles presuming that this will make actors interpret available information in more similar ways. The following example shows that when conflicting frames are present, agreement on principles will not always bring actors closer. 
The principle of intergenerational equity is central to sustainable development according to the Brundtland definition (WCED, 1987). Both those in favour of sludge use and their opponents use this principle as an argument. For the opponents, equity between generations means that the present generation has no right to contaminate arable land to such an extent that its long-term productivity is endangered. In contrast, proponents of sludge use emphasise the limited availability of relatively pure and easily extractable phosphorus and argue that today's generation should limit the extraction of this resource for the benefit of future generations. Hence, the principle of intergenerational equity can be interpreted according to the two different frames in such ways that it supports the already existing beliefs and therefore it cannot contribute to a resolution of the controversy; the frames seem to be immune to change.

This example illustrates that public disputes are often not struggles between principles. In the words of Warnke: "Our debates are not moral debates over which principles we should adopt but rather interpretative debates over the meaning of the principles we already possess" (Warnke, 1999, p. 8). Warnke suggested that recognition of the interpretative status of our own position is a first step towards increased openness to alternative perspectives. Warnke's recommendation resembles ideas expressed by many other scholars. Calls for increased openness among actors to each other's perspectives have been plentiful, as discussed by van Eeten (1999), who also criticised these recommendations. Such advice is based on the view that actors do not make enough effort to listen to each other. Van Eeten found that this is seldom the case and argued that efforts aiming at increasing actors' openness need to be complemented by initiatives that address the structural properties of a deadlock and help the actors see the controversy in a new light.

\subsection{Argument versus critique}

In controversies it is common that some actors present a preferred option and arguments for that option, while other actors only criticise options presented by others by pointing out weaknesses in their supporting arguments. In a study of a Dutch controversy over dike improvements, van Eeten (1999) discussed this kind of asymmetric relationship, and pointed out that such situations will often end up in deadlocks. In the sludge controversy, the wastewater sector represents the clearest option of all actors: to use sludge in agriculture. Some actors from the food industry (Berglund, 2001) and the environmental movement (Lönngren, 2004) oppose agricultural use without expressing any clear opinions on how sludge should be handled. They believe the main responsibility for solving this issue lies with the municipalities.

Although it is fully legitimate to criticise proposed options without presenting a solution, and although such criticisms may be equally or more valid as the opposed arguments, the structural asymmetry between argument and critique makes it difficult to handle both equally. For a policy maker, it can be difficult to use a critique in a productive way. The solution offered by van Eeten (1999) is to assist those actors that only criticise others' arguments so they develop preferred options of their own. In most cases, this will not resolve the controversy, but it will make the actors more focused on solutions. To be successful, van Eeten's proposal depends on the willingness of all actors to engage in designing solutions even to problems they do not feel directly responsible for. Hence, under such circumstances, 


\section{COALITION LEVEL:}

\section{Position on sludge use in agriculture}

\section{Preferred option}

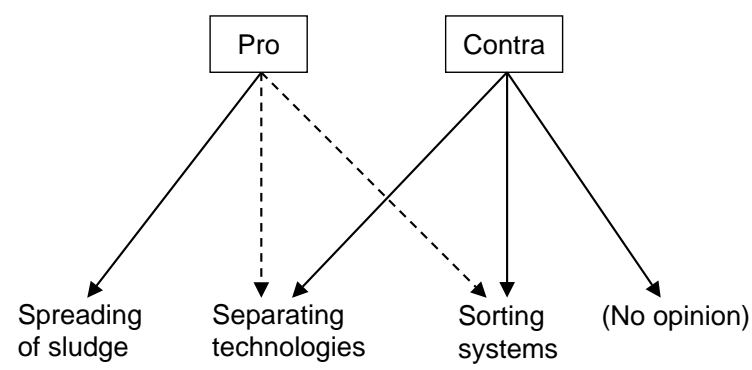

Fig. 3. Two levels for coalition formation among actors. Dashed arrows indicate that proponents of direct spreading of sludge support second-best options when spreading is not feasible. Therefore, coalitions for separating or sorting options can include both proponents and opponents of spreading.

an essential part of policy making is to encourage actors to take active and constructive part in the policy community.

\subsection{Coalition formation—sorting versus separating technologies}

Actors can form coalitions on different levels (Fig. 3). The first level is the initial opposition between proponents and opponents of sludge use. Irrespective of their policy preferences, opponents can work together to stop the use of sludge. However, some opponents have noticed that merely criticising agricultural use is not very effective; the critique is more constructive and easier to take into account by policy makers if it is combined with a preferred option. Some proponents of sludge use maintain that this is the best option despite the criticism, while others no longer try to convince the opponents and therefore have turned to other options. Consequently, in the coalitions supporting new options (the sorting systems and the separation technologies), opponents and proponents of sludge use in agriculture may find themselves working together. Such co-operation may be problematic after several years of conflict.

Separating technologies can be described as add-on solutions and do not require changes of wastewater systems and treatment plants or the organisations that operate these systems. Sorting systems, in contrast, entail extensive changes that may be seen as threats by the wastewater sector (Söderberg, 1999). Furthermore, compared to other options, the implementation of sorting systems is slow and it does not solve today's problem of sludge disposal. For these reasons, it is easy to see why the wastewater sector in general prefers separating technologies as their second-best option.

For economic reasons, municipalities that invest in separating technologies are unlikely to be willing to construct sorting systems for a long time. Flexibility will be lost once one option is chosen. This lock-in effect is an additional source of conflict between the proponents of the two options. The actors' policy preferences can only be understood as the result of a combination of factors: available options' compatibility with existing infrastructure, their investment costs, the perceived quality of the recycled product, the time 
required for implementation, the difficulties of working together with (former) antagonists, and the economic lock-in effect.

\subsection{Fairness and blame}

As has been shown, the sludge controversy contains a number of different issues some of which lie beyond the control of the actors involved. The widespread use of chemicals and metals in modern society is presumably the most important of those external issues. For example, municipalities have limited possibility to influence flows of cadmium (Lindqvist-Östblom and Eklund, 2001). Thus, the actors feel that they are unfairly blamed for not being able to comply with the politically decided goal to recycle phosphorus. This feeling is perhaps most strongly felt by those working in the wastewater sector. To generate environmental problems by spreading toxic substances on farmland conflicts with their self image of environmental protectors (Söderberg, 1999). It is understandable if this causes cognitive dissonance and stress among many people in that sector.

\section{Discussion and conclusions}

The analysis has identified a number of factors that make the sludge controversy intractable. Among these is the over-reliance on facts as a way to resolve the issue. We emphasise the need for actors to also engage in discussions on values and beliefs (Fig. 4). Such discussions can, even if they do not lead to consensus, broaden the actors' perspectives and increase their mutual understanding.

Principles such as the precautionary principle and intergenerational equity do not have unequivocal meanings; they need to be interpreted in the specific context to give guidance. In our view, the actors in the sludge controversy have not worked out shared understandings on the level of principles. Not before such understandings are reached can principles form the basis for substantial agreements and joint action.

We have also found the need for policy makers, in this case the Environmental Protection Agency (NV), to develop a management style that goes beyond the traditional role of regulator. This style needs to be based on process leadership that can encourage actors in the loosely defined network to take part in joint problem solving. This observation on the changing role of policy making is in line with Glasbergen (1995), Kickert et al. (1997) and Ryan (2001).

It was noted that actors tend to give science and scientific results a prominent role. It was also shown that scientific investigations reflect some specific perspective and are, due to their approach and emphasis, more meaningful to some specific actors than to others. When taking a particular problem definition as starting point for investigations, that problem definition is also given legitimacy. This indicates that researchers who act as advisors for controversial situations need to be well aware of the social contexts in which results will be used; what perspectives are supported by the approach chosen and how a certain kind of results fits with different frames of thinking.

We believe that our analysis of the controversy demonstrates some new ways of discussing its properties and causes. We hope that the study thereby also can give actors in other 


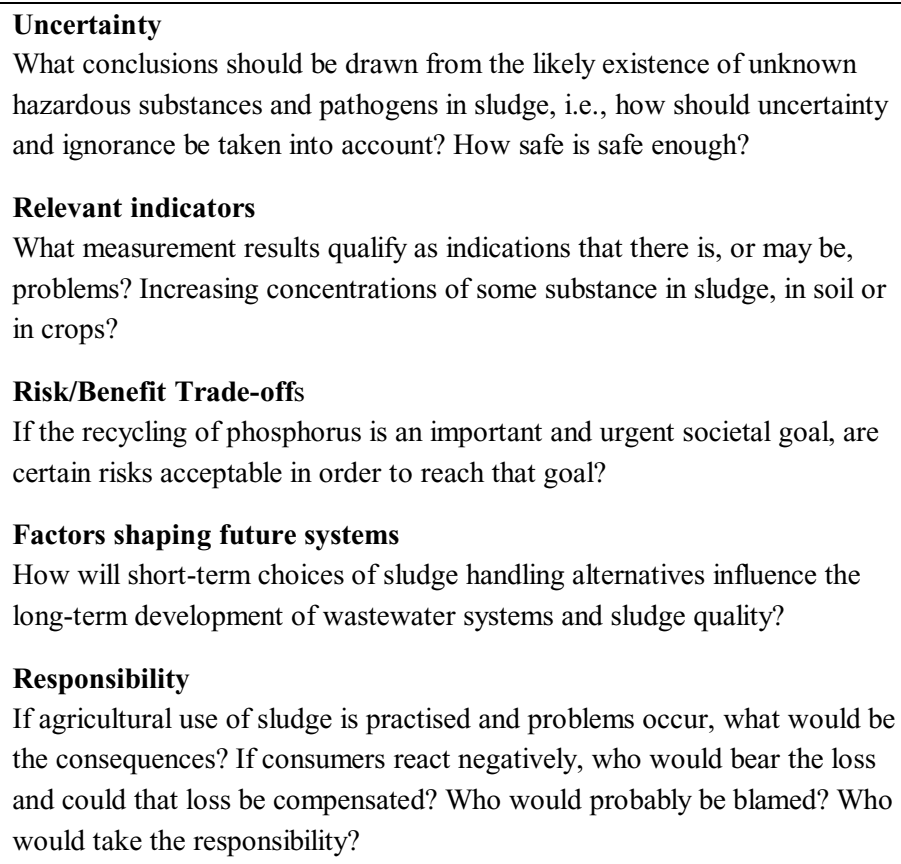

Fig. 4. Some of the value-based questions that actors in the sludge controversy need to address explicitly to promote a more constructive dialogue.

environmental controversies lenses through which to better understand the situations in which they are involved.

\section{Acknowledgements}

This project was supported by Formas, the Swedish Research Council for Environment, Agricultural Sciences and Spatial Planning. An earlier version of this paper was presented at the 10th International Conference of the Greening of Industry Network (GIN), Göteborg, Sweden, 23-26 June, 2002. The authors would like to thank Göran Sundqvist (Göteborg University), Henriette Söderberg, and Margareta Lundin (both at Chalmers University of Technology) for their helpful comments on that draft.

\section{References}

Berglund M. Livsmedelssektorns syn på växtnäring från stad till land [The food sector's view on plant nutrients from cities to farmland]. M.Sc. Thesis. Report 244. Uppsala: Department of Agricultural Engineering, Swedish University of Agricultural Sciences, 2001 (in Swedish).

Bowler IR. Recycling urban waste on farmland: an actor-network interpretation. Appl Geogr 1999;19:29-43. 
Brante T. Kontroversstudier-ett forskningsprogram, del 2 [Controversy studies: a research programme, Part 2]. VEST-Tidskrift för vetenskapsstudier 1990;4:3-17 (in Swedish).

Brante T, Fuller S, Lynch W, editors. Controversial science: from content to contention. Albany: State University of New York Press, 1993.

EC. Disposal and recycling routes for sewage sludge. Part 1. Sludge use acceptance report. Luxembourg: European Communities, 2001.

EEA. Review of selected waste streams: sewage sludge, construction and demolition waste, waste oils, waste from coal-fired power plants and biodegradable municipal waste. Copenhagen: European Environmental Agency, 2002.

Ekvall A. Metal speciation and toxicity in sewage sludge. Dissertation. Göteborg: Department of Sanitary Engineering, Chalmers University of Technology, 1995.

Engelhardt Jr T, Caplan A, editors. Scientific controversies. Cambridge: Cambridge University Press, 1987.

Glasbergen P, editor. Managing environmental disputes: network management as an alternative. Dordrecht: Kluwer Academic Publishers, 1995.

Hultman B, Levlin E, Stark K. Swedish debate on sludge handling. In: Płaza E, Levlin E, Hultman B, editors. Proceedings of a Polish-Swedish Seminar on sustainable municipal sludge and solid waste handling, Cracow, May 29, 2000. Report No 7. Stockholm: Department of Civil and Environmental Engineering, Royal Institute of Technology, 2000.

Johansson B. Enkät speglar slam i dag och i morgon [Survey reflects sludge today and tomorrow]. Svenskt Vatten 2002;1:38 (in Swedish).

Kickert WJM, Klijn E-H, Koppenjan JFM, editors. Managing complex networks: strategies for the public sector. London: Sage, 1997.

Krogmann U, Boyles LS, Martel CJ, McComas KA. Biosolids and sludge management. Water Environ Res 1997;69(4):534-50.

Lindqvist-Östblom A, Eklund M. Cadmium in sewage sludge in a Swedish region: sources and reduction opportunities. Environ Eng Policy 2001;2:145-54.

Lönngren M. Heliga åkrar eller kretslopp av näring - en skitrapport [Sacred fields or recycling of nutrients: a shit report]. Stockholm: Svenska Naturskyddsföreningen, 2004 (in Swedish).

McLaughlin MJ, Parker DR, Clarke JM. Metals and micronutrients-food safety issues. Field Crops Res 1999;60:143-63.

Palmquist H. Hazardous substances in wastewater systems: a delicate issue for wastewater management. Lic. Thesis. Luleå: Department of Environmental Engineering, Luleå University of Technology, 2001.

Ryan C. Leadership in collaborative policy-making: an analysis of agency roles in regulatory negotiations. Policy Sci 2001;34:221-45.

Schön D, Rein M. Frame reflection: toward the resolution of intractable policy controversies. New York: BasicBooks, 1994.

SEPA. de Facto 2001: environmental objectives and fundamental principles. Stockholm: Swedish Environmental Protection Agency, 2001.

Söderberg H. Kommunerna och kretsloppet: avloppssektorns förändring från rening till resurshantering [Recycling municipalities: the change of sewage treatment from reduction to resource management]. Dissertation. Linköping Studies in Arts and Science No. 194. Department of Water and Environmental Studies, The Tema Institute, Linköping University, 1999 (in Swedish with English summary).

van Eeten M. Dialogues of the deaf: defining new agendas for environmental deadlocks. Delft: Eburon, 1999.

Warnke G. Legitimate differences: interpretation in the abortion controversy and other public debates. Berkeley: University of California Press, 1999.

WCED. Our common future. Report of the World Commission on Environment and Development. Oxford: Oxford University Press, 1987. 